\title{
Synthesis, XRD \& SEM Studies of Zinc Substitution in Nickel Ferrites by Citrate Gel Technique
}

\author{
K. Rama Krishna ${ }^{1}$, D. Ravinder ${ }^{2 *}$ K. Vijaya Kumar ${ }^{3}$, Ch. Abraham Lincon ${ }^{4}$ \\ ${ }^{1}$ Department of Physics, Malla Reddy College of Engineering \& Technology, Secunderabad, India; ${ }^{2}$ Department of Physics, P. G. \\ College of Science, Osmania University, Hyderabad, India; ${ }^{3}$ Department of Physics, Jawaharlal Nehru Technological University, \\ Hyderabad, College of Engineering, Nachupally (Kondagattu), India; ${ }^{4}$ Department of Chemistry, P. G. College of Science, Osmania \\ University, Hyderabad, India. \\ Email: *ravindergupt28@rediffmail.com
}

Received February $3^{\text {rd }}$, 2012; revised March $3^{\text {rd }}$, 2012; accepted March $15^{\text {th }}, 2012$

\begin{abstract}
$\mathrm{Ni}-\mathrm{Zn}$ ferrite with a nominal composition of $\mathrm{Ni}_{1-\mathrm{X}} \mathrm{Zn}_{\mathrm{X}} \mathrm{Fe}_{2} \mathrm{O}_{4}(\mathrm{X}=0$, 0.2, 0.6, 0.8, 0.9 and 1.0) ferrite powders have been successfully prepared at a very low temperature $\left(180^{\circ} \mathrm{C}\right)$ by a novel auto combustion process using citric acid as a coordinating agent. Phase purity of the solid solutions has been confirmed by X-ray diffraction. Morphological, elemental composition characterizations of the prepared samples were performed by high resolution scanning electron microscopy and energy dispersive spectroscopy (EDS). Magnetic properties of all samples are obtained by using VSM (Vibrating Sample Magnetometer) in the range of $10 \mathrm{~K}$ oe. The saturation magnetization values of the samples are carried out from the B-H loop. The effect of composition on saturation magnetization and magnetic moment are studied in this paper. The results showed that Saturation magnetization and magnetic moment values increases gradually as $\mathrm{Zn}^{2+}$ composition increases, it reaches maximum value $70.28 \mathrm{emu} / \mathrm{gm}$ for $(\mathrm{X}=0.6)$ and decreases further with increasing $\mathrm{Zn}^{2+}$ composition.
\end{abstract}

Keywords: Ni-Zn Ferrite; Citrate Precursor Auto Combustion; Saturation Magnetization; Magnetic Moment

\section{Introduction}

Among the different mixed ferrites, Ni-Zn ferrites have a good utility as a conducted noise suppressor material in various electromagnetic interfaces compared to other ferrites [1,2]. Because of their high resistivity, relatively high permeability and low eddy current loss $[3,4]$. These soft magnetic materials, crystallizes in the spinel structure of the type $\left(\mathrm{Zn}_{1-\mathrm{x}} \mathrm{Fe}_{\mathrm{x}}\right)\left(\mathrm{Ni}_{\mathrm{x}} \mathrm{Fe}_{2-\mathrm{x}}\right) \mathrm{O}_{4}$, where the metallic cations $\mathrm{Fe}^{3+} / \mathrm{Zn}^{2+}$ occupy the tetrahedral A sites, and the metallic cations $\mathrm{Fe}^{3+} / \mathrm{Ni}^{2+}$ occupy the octahedral B sites[5,6]. It is known that magnetic properties of ferrites are sensitive to preparation technique and their microstructures [7]. The electrical and magnetic properties of such ferrites depend strongly on distribution of cations at the tetrahedral (A) and octahedral (B) sites in the lattice [8-10]. It is well known that zinc ions can be used to alter the saturation magnetization. It is believed that the addition of zinc ions also affects the lattice parameter and it would therefore be expected to change the Curie temperature of the material [11]. The substitution of divalent ions in pure ferrites leads to the modification of the structural, electrical and magnetic properties [12]. The conventional solid-state reaction route is widely used for the production of ferrite

\footnotetext{
${ }^{*}$ Corresponding author.
}

because of its low cost and suitability for large scale production. The citrate method is used to speed up the synthesis of complex materials. It is a simple process, which offers a significant saving in time, energy consumption over the traditional methods. In this method the metal ions or complexes are immobilized on atomic scale (inside the matrix), which allows to obtain oxides at temperature lower than ones produced in solid state reaction. This method also produces homogenous and stoichiometrical oxides. Several researchers have reported the synthesis of Ni-Zn ferrites using different techniques like, refluxing process [13], ceramic [14], hydrothermal [15], combustion [16], co-precipitation [17], reverse micelle process [18], spark plasma sintering [19], micro emulsion [20] and ball milling, etc. In this work, we present the results of systematic doping of non-magnetic Zn content on the magnetic properties of Ni-Zn ferrite synthesized by citrate method.

\section{Experimental}

The starting materials were nickel nitrate, zinc nitrate, iron nitrate, citric acid and ammonia all of analytical grade. The solution of nickel nitrate $\left(\mathrm{Ni}\left(\mathrm{NO}_{3}\right)_{2} \cdot 6 \mathrm{H}_{2} \mathrm{O}\right.$, ferric nitrate $\left(\mathrm{Fe}\left(\mathrm{NO}_{3}\right)_{3} \cdot 9 \mathrm{H}_{2} \mathrm{O}\right)$ and zinc nitrate $\left(\mathrm{Zn}\left(\mathrm{NO}_{3}\right)_{2} \cdot 6 \mathrm{H}_{2} \mathrm{O}\right)$ in their stoichiometry were dissolved in a deionized water. 
Citric acid was then added to the prepared aqueous solution to chelate $\mathrm{Ni}^{2+}, \mathrm{Zn}^{2+}$ and $\mathrm{Fe}^{3+}$ in the solution. The molar ratio of citric acid to total moles of nitrate ions was adjusted at 1:3. The mixed solution was neutralized to $\mathrm{pH} 7$ by adding ammonia $\left(\mathrm{NH}_{3}\right)$ solution. The neutralized solution was evaporated to dry ness by heating at $100^{\circ} \mathrm{C}$ on a hot plate with continuous stirring, until it becomes viscous and finally formed a very viscous gel, increasing the temperature up to $200^{\circ} \mathrm{C}$ lead to ignition of gel. The dried gel burnt completely in a self propagating combustion manner to form a loose powder. Finally the burnt powder was calcined in air at temperature of $1000^{\circ} \mathrm{C}$ for one hour to obtain spinel phase. Afterwards the powder was pressed into pellets of thickness $3 \mathrm{~mm}$ and a diameter of $10 \mathrm{~mm}$ with press by applying a pressure of 2 tons $/ \mathrm{in}^{2}$. The final sintering was done at $1000^{\circ} \mathrm{C}$. The structural characterizations of all samples were carried out by
X-ray diffraction (XRD) and conforms the well defined single phase spinel structure. XRD data were taken at room temperature using $\mathrm{CuK} \alpha$ radiation. Morphological, elemental composition characterizations of all prepared samples were performed by high resolution scanning electron microscopy, and energy dispersive spectroscopy (EDS). The Magnetic measurements were carried out by using Vibrating sample magnetometer (VSM) in the range of $10 \mathrm{~K}$ oe.

\section{Results and Discussions}

The X-ray diffraction patters of the samples are shown in Figure 1. All the zinc substituted nickel ferrites of the various compositions show the crystalline cubic spinel structure. The sharp peaks represents that all ferrites are crystalline nature of single phase. The lattice parameter of individual composition was calculated by using the formula:

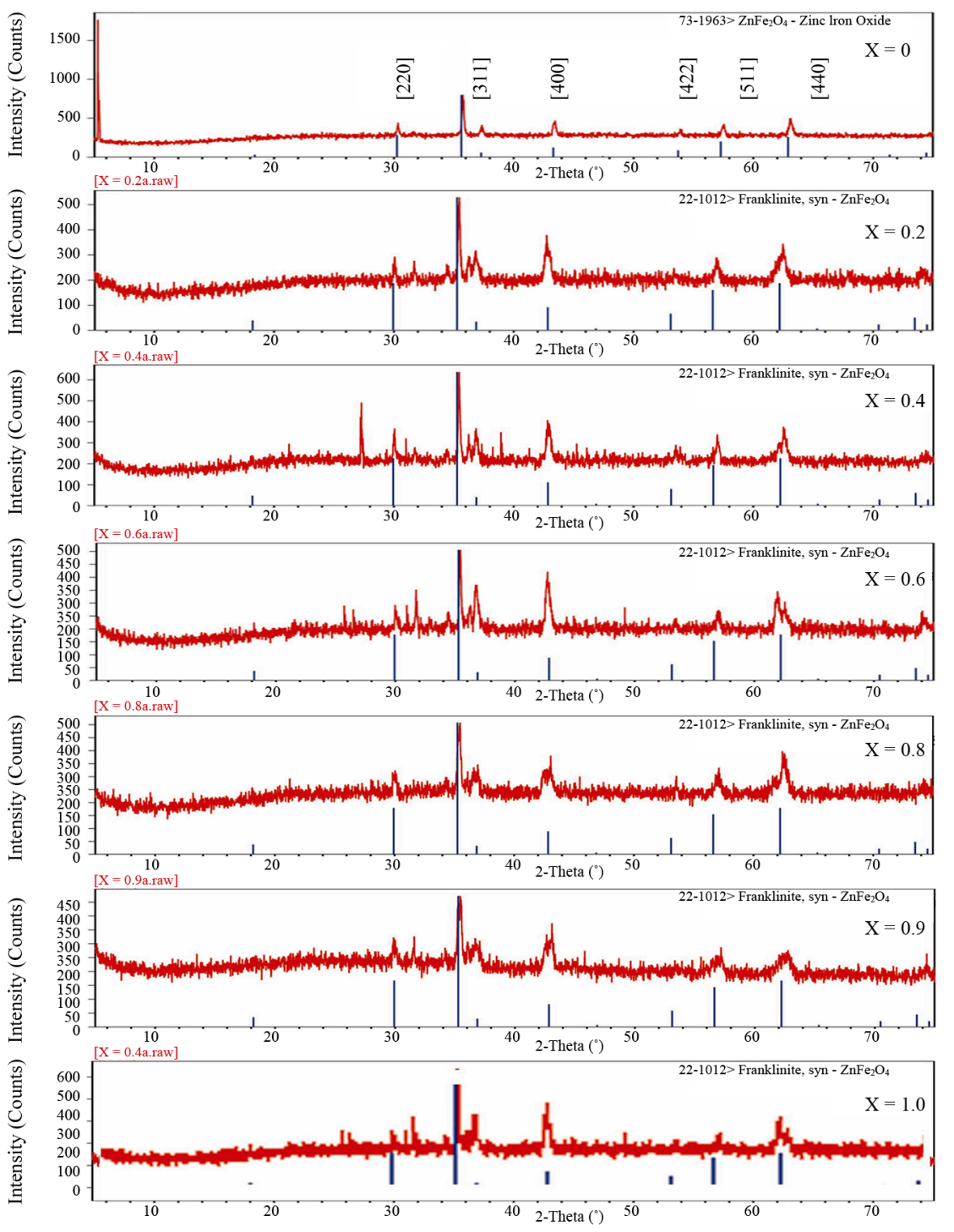

Figure 1. X-ray diffraction studies of mixed Ni-Zn ferrites. 


$$
\mathrm{a}=\mathrm{d}\left(\mathrm{h}^{2}+\mathrm{k}^{2}+\mathrm{l}^{2}\right)^{1 / 2}[21]
$$

where, a = lattice constant; $\mathrm{d}$ = inter planar distance; and $(\mathrm{h}, \mathrm{k}, \mathrm{l})$ are the Miller indices.

The calculated lattice constant " $a$ " is seen to increase from $8.33 \AA$ to $8.52 \AA$ with increase in zinc content as reported in Table 1. The variation of lattice parameter with zinc composition is shown in Figure 2. The lattice parameter is found vary linearly with increasing zinc concentration, there by indicating that the Ni-Zn ferrite system obeys Vegard's law [22]. A similar behavior of lattice constant with dopant concentration was observed by several investigators in various ferrite systems [23-25]. The variation in lattice constant with zinc content can be explained on the basis of the ionic radii of $\mathrm{Zn}^{2+}(0.82 \AA)$ ions is higher than that of $\mathrm{Ni}^{2+}(0.78 \AA)$ [26].

The scanning electron microscope (SEM) images of all prepared samples are given in Figure 3.

Figure 4 shows the EDS pattern obtained for all the samples which gives the elemental and atomic composition in the samples. The compounds show the presence of $\mathrm{Ni}, \mathrm{Fe}, \mathrm{Zn}$ and $\mathrm{O}$ without precipitating cations.

Table 1. Lattice parameter data for mixed Ni-Zn ferrite.

\begin{tabular}{ccc}
\hline S. No. & Ferrite Composition & Lattice Parameter $(\AA)$ \\
\hline 1 & $\mathrm{X}=0$ & 8.33 \\
2 & $\mathrm{X}=0.2$ & 8.43 \\
3 & $\mathrm{X}=0.4$ & 8.45 \\
4 & $\mathrm{X}=0.6$ & 8.46 \\
5 & $\mathrm{X}=0.8$ & 8.48 \\
6 & $\mathrm{X}=0.9$ & 8.50 \\
7 & $\mathrm{X}=1.0$ & 8.52 \\
\hline
\end{tabular}

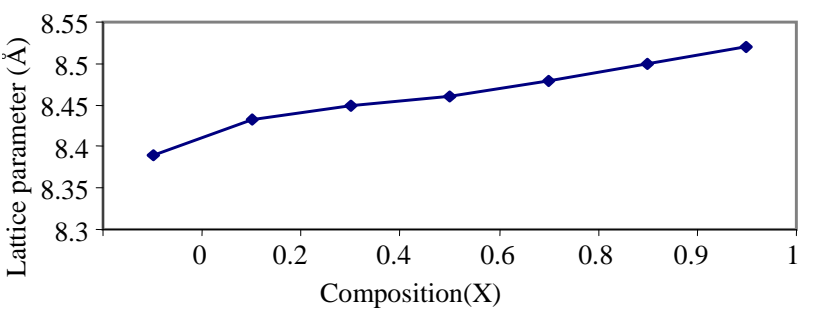

Figure 2. Variation of lattice parameter with composition.

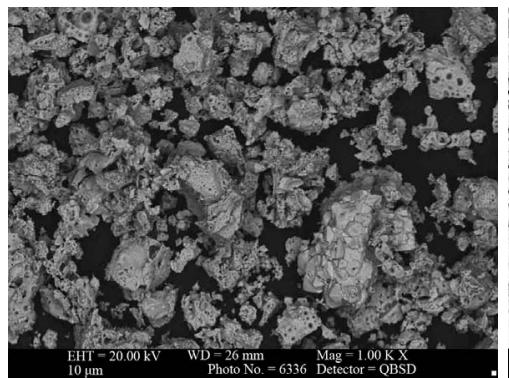

$\mathrm{X}=0$

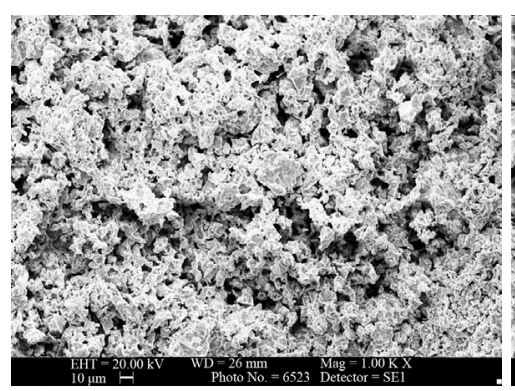

$\mathrm{X}=0.6$

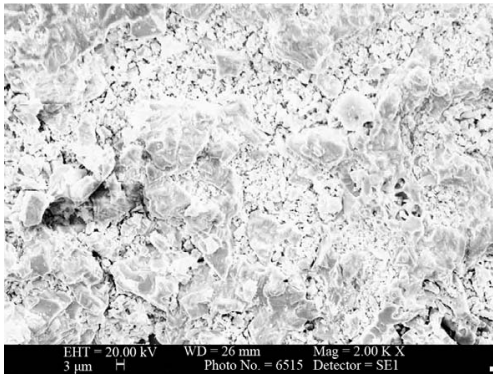

$\mathrm{X}=0.2$

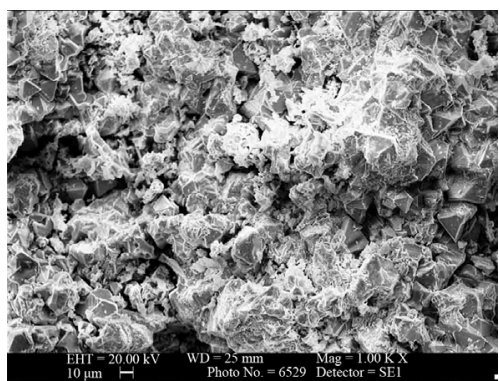

$\mathrm{X}=0.8$

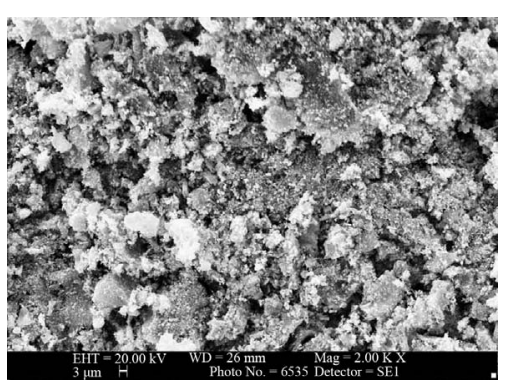

$\mathrm{X}=1$

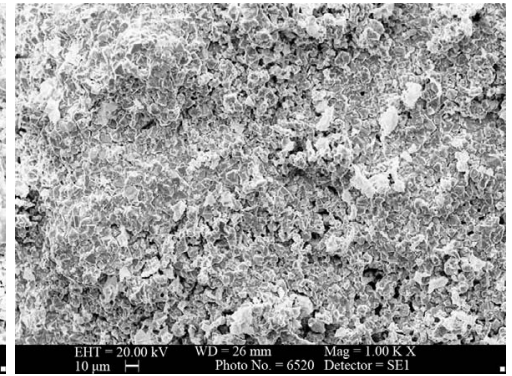

$\mathrm{X}=0.4$

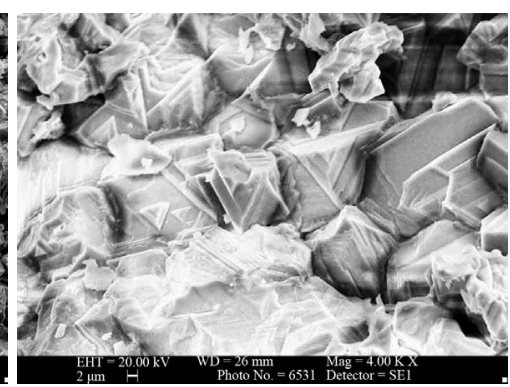

$\mathrm{X}=0.9$

Figure 3. SEM images of Ni-Zn ferrites. 

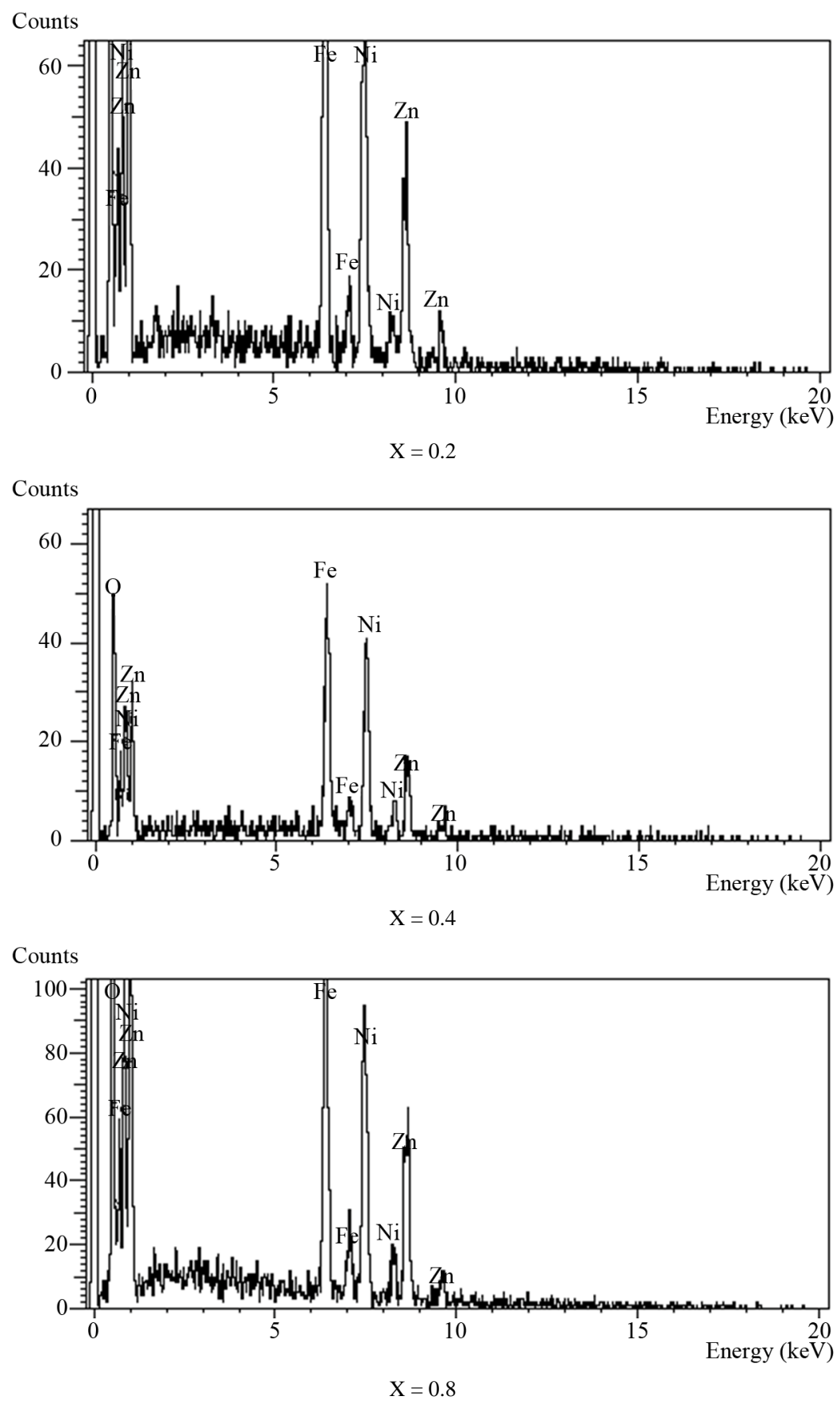

Figure 4. EDS of Ni-Zn ferrites.

Figure 4 shows the EDS pattern obtained for all the samples which gives the elemental and atomic composition in the samples. The compounds show the presence of $\mathrm{Ni}, \mathrm{Fe}, \mathrm{Zn}$ and $\mathrm{O}$ without precipitating cations.

$\mathrm{X}$-ray density ( $\mathrm{dx}$ ) was determined using the following relation

$$
\mathrm{Dx}=\mathrm{ZM} / \mathrm{Na}^{3}
$$

where $\mathrm{Z}$ is the number of molecules per unit cell $(\mathrm{Z}=8)$, " $\mathrm{M}$ " is the molecular weight and " $\mathrm{N}$ " is the Avogadro's number.

The bulk density of the specimens has been determined accurately by the hydrostatic method and the percentage of porosity was also calculated. The values of the bulk density, X-ray density and the percentage of porosity for Ni-Zn ferrites are given in Table 2. It can be seen from the table that the bulk density increases and the porosity decreases progressively with addition of zinc to nickel ferrite. Zinc ferrite having the least porosity, this conforms the observation that the addition of zinc to nickel 
Table 2. Bulk density-ray density and porosity data for mixed Ni-Zn ferrites.

\begin{tabular}{ccccc}
\hline S. No. & $\begin{array}{c}\text { Ferrite } \\
\text { composition }\end{array}$ & $\begin{array}{c}\text { Bulk density } \\
\mathrm{Gm} \mathrm{cm}^{3}\end{array}$ & $\begin{array}{c}\text { X-ray density } \\
\mathrm{Gm} / \mathrm{cm}^{3}\end{array}$ & Porosity \\
\hline 1 & $\mathrm{X}=0$ & 4.68 & 5.02 & 6.6 \\
2 & $\mathrm{X}=0.2$ & 4.88 & 5.14 & 5.06 \\
3 & $\mathrm{X}=0.4$ & 5.04 & 5.28 & 4.55 \\
4 & $\mathrm{X}=0.6$ & 5.18 & 5.42 & 4.43 \\
5 & $\mathrm{X}=0.8$ & 5.42 & 5.64 & 3.90 \\
6 & $\mathrm{X}=0.9$ & 5.68 & 5.88 & 3.40 \\
7 & $\mathrm{X}=1.0$ & 5.80 & 5.99 & 3.01 \\
\hline
\end{tabular}

ferrite results the densification of the material [27].

The variation of bulk density with zinc content for mixed Ni-Zn ferrite is shown in the Figure 5. It may be seen from the figure that bulk density increases linearly with the increase of zinc content.

\subsection{Magnetic Properties}

The magnetic measurements of all the samples were measured by using Vibrating sample magnetometer in the range of $10 \mathrm{Koe}$, which shows that samples exhibited magnetic behavior.

From the VSM measurements, hysteresis loops are plotted as shown in the Figure 6. The value of saturation magnetization was carried out from hysteresis loops. The variation of saturation magnetization with composition is shown in the Figure 7. It is seen from the figure that the value of saturation magnetization increases gradually and reaches to the maximum value of $70.28 \mathrm{emu} / \mathrm{gm}$ for $\mathrm{X}=$ 0.6 composition and then decreases gradually while $\mathrm{Zn}^{+2}$ composition increases. The behavior of this plot is similar to the [28]. The dependence of saturation magnetization is explained in terms of spin-disorder and spin-canting. In mixed $\mathrm{Ni}-\mathrm{Zn}$ ferrite, the $\mathrm{Zn}^{2+}$ ions concentrate preferentially in the A site and the $\mathrm{Ni}^{2+}$ ions in $\mathrm{B}$ site in cubic spinel lattice. When the concentration of $\mathrm{Fe}^{3+}$ ions in the A site is diluted by low concentration of diamagnetic substances such as $\mathrm{Zn}^{2+}$, As the $\mathrm{Zn}^{2+}$ content increases the exchange interactions are weakened and the $\mathrm{B}$ spins are no longer held rigidly parallel to the few remaining $\mathrm{A}$ spins .The decrease in B sub lattice moment, interpreted as spin departure from co linearity causes the effect known as canting. Sattar [29] also described this effect in samples of $\mathrm{Cu}-\mathrm{Zn}$ ferrite.

\subsection{Magnetic Moment}

Magnetic Moment is calculated in Bhor Magnetron using the following relation [30] and tabulated in the Table 3

$$
\mu_{\mathrm{B}}=\mathrm{M} \times \mathrm{Ms} / 5585
$$

$\mathrm{M}=$ Molecular weight of particular composition; $\mathrm{Ms}=$ Saturation Magnetization.

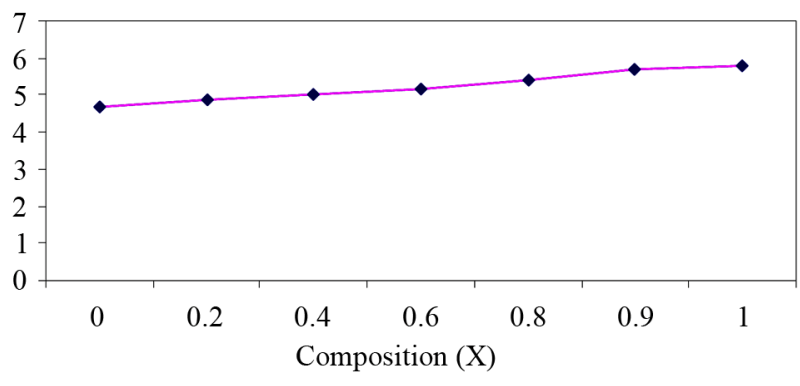

Figure 5. Variation of bulk density with composition.

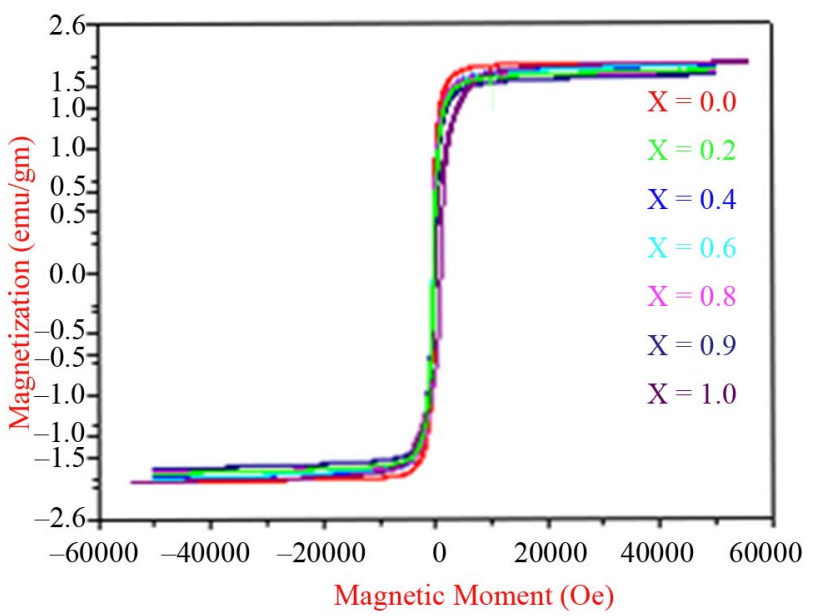

Figure 6. Magnetic hysteresis loops drawn between magnetic field and magnetic moment.

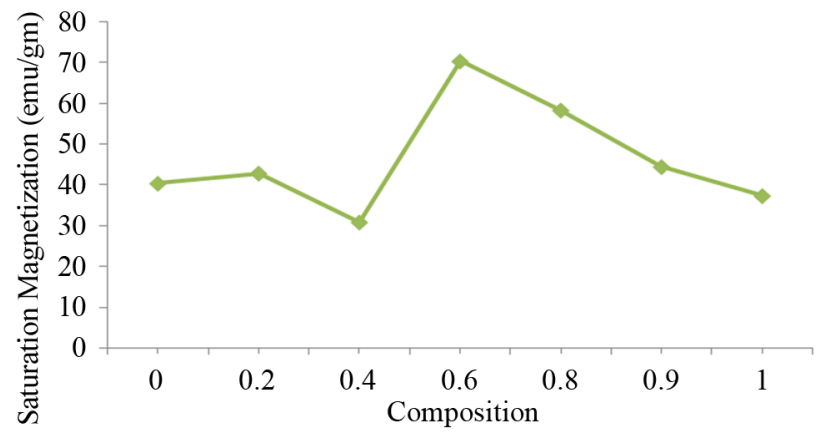

Figure 7. Variation of saturation magnetization with composition.

Table 3. Saturation magnetization and magnetic moment for mixed Ni-Zn ferrites.

\begin{tabular}{ccc}
\hline Composition & $\begin{array}{c}\text { Saturation magnetization } \\
\text { (emu/gm) }\end{array}$ & $\mu_{\mathrm{B}}$ (Bhor magnetron) \\
\hline $\mathrm{NiFe}_{2} \mathrm{O}_{4}$ & 40.32 & 1.69 \\
$\mathrm{Ni}_{0.8} \mathrm{Zn}_{0.2} \mathrm{Fe}_{2} \mathrm{O}_{4}$ & 42.79 & 1.80 \\
$\mathrm{Ni}_{0.6} \mathrm{Zn}_{0.4} \mathrm{Fe}_{2} \mathrm{O}_{4}$ & 30.83 & 1.90 \\
$\mathrm{Ni}_{0.4} \mathrm{Zn}_{0.6} \mathrm{Fe}_{2} \mathrm{O}_{4}$ & 70.28 & 2.99 \\
$\mathrm{Ni}_{0.2} \mathrm{Zn}_{0.8} \mathrm{Fe}_{2} \mathrm{O}_{4}$ & 58.26 & 2.55 \\
$\mathrm{Ni}_{0.1} \mathrm{Zn}_{0.9} \mathrm{Fe}_{2} \mathrm{O}_{4}$ & 44.40 & 1.91 \\
$\mathrm{ZnFe}_{2} \mathrm{O}_{4}$ & 37.28 & 1.62 \\
\hline
\end{tabular}


It can be seen from the table that the ferrite with composition $\mathrm{Ni}_{0.4} \mathrm{Zn}_{0.6} \mathrm{Fe}_{2} \mathrm{O}_{4}$ shows highest value of magnetic moment. It is evident from the Table 1, that the magnetic moment increases with $\mathrm{Zn}$ composition up to $\mathrm{X}=0.6$ and then decreases. It can be concluded that as $\mathrm{Zn}$ replaces magnetic ions from "A" sites. The magnitude of A site moment decreases but the difference between the A site and B site moment increases, as a result magnetic moment increases but the decrease in magnetic moment after $\mathrm{X}=0.6$ indicates the possibility of canted spin (non-collinear) structure in the present system. The decrease in magnetic moment with increase $\mathrm{Zn}^{2+}$ concentration indicating ferromagnetic behavior which decrease with increasing $\mathrm{Zn}^{2+}$ [31].

\section{Conclusion}

The mixed Ni-Zn ferrite samples are prepared and we can observe the following conclusions. The lattice parameter increases with increase of zinc content, the bulk density increases linearly with zinc content, SEM pictures shows that the morphology of the particles is very similar. The values of saturation magnetization, magnetic moment increases gradually reaches the maximum value and then decreases as $\mathrm{Zn}^{2+}$ composition is increased. The ferrite with composition $X=0.6$ shows highest value of saturation magnetization and magnetic moment.

\section{Acknowledgements}

The authors are grateful to Prof. Naidu Ashoak, Principal, Nizam College, Osmania University, and Hyderabad for his encouragement in research work. One of the authors K. Rama Krishna is grateful to V. S. K. Reddy, Principal, Malla Reddy College of Engineering \&Technology, Hyderabad. And the author K. Vijaya Kumar is grateful to Dr. Koorapati Eshwara Prasad, Principal JNTUH College of Engineering, Nachupally, Karim Nagar (Dist).

\section{REFERENCES}

[1] N. Matsushita, K. Kondo, S. Yoshida, M. Tada, M. Yoshimura and M. Abe, "Ni-Zn Ferrite Films Synthesized from Aqueous Solution Usable for Sheet-Type Conducted Noise Suppressors in GHz Range,” Journal of Electroceramics, Vol. 16, No. 4, 2006, pp. 557-560. doi:10.1007/s10832-006-9918-9

[2] K. Kondo, T. Chiba, H. Ono, S. Yoshida, Y. Shimada, N. Matsushita and M. Abe, "Conducted Noise Suppression Effect up to $3 \mathrm{GHz}$ by Ni-Zn Ferrite Film Plated at $90^{\circ} \mathrm{C}$ Directly onto Printed Circuit Board,” Journal of Applied Physics, Vol. 93, No. 10, 2003, pp. 7130-7132.

[3] V. L. O. de Brito, A. C. da C. Migliano, L. V. Lemos and F. C. L. Melo, "Ceramic Processing Route and Characterization of a Ni-Zn Ferrite in Application in a Pulsed-Current Monitor," Progress in Electromagnetics Research, Vol. 91, 2009, pp. 303-318. doi:10.2528/PIER09031603
[4] T. Jahanbin and M. Hashim, "Magnetic and Morphological Characterization of Ni-Zn Ferrite Prepared from Nano Size Starting Powder via Coprecipitation Technique," Solid State Science and Technology, Vol. 17, No. 2, 2009, pp. 243-249.

[5] S. Albuquerque, J. D. Ardisson, W. A. A. Macedo and M. C. M. Alves, "Nanosized Powders of Ni-Zn Ferrite: Synthesis, Structure, and Magnetism,” Journal of Applied Physics, Vol. 87, No. 9, 2000, pp. 4352-4358.

[6] B. D. Cullity, "Elements of X-Ray Diffraction,” Addison-Wesley Publishing Company, Inc., Boston, 1956.

[7] H. Su, H. W. Zhang, X. L. Tang, Y. L. Jing and Y. L. Liu, "Effects of Composition and Sintering Temperature on Properties of NiZn and NiCuZn Ferrites," Journal of Magnetism and Magnetic Materials, Vol. 310, No. 1, 2007, pp. 17-21. doi:10.1016/j.jmmm.2006.07.022

[8] J. L. Dormann and M. Nogues, "Magnetic Structures in Substituted Ferrites,” Journal of Physics: Condensed Matter, Vol. 2, No. 5, 1990, pp. 1223-1237. doi:10.1088/0953-8984/2/5/014

[9] N. Rezlescu, E. Rezlescu, C. Pasnicu and M. L. Craus, "Effects of the Rare-Earth Ions on Some Properties of a Nickel-Zinc Ferrite,” Journal of Physics: Condensed Matter, Vol. 6, No. 29, 1994, pp. 5707-5716. doi:10.1088/0953-8984/6/29/013

[10] A. E. Virden and K. O’Grady, "Structure and Magnetic Properties of NiZn Ferrite Nanoparticles," Journal of Magnetism and Magnetic Materials, Vol. 290-291, Part 2, 2005, pp. 868-870. doi:10.1016/j.jmmm.2004.11.398

[11] A. M. El-Sayed, "Influence of Zinc Content on Some Properties of Ni-Zn Ferrites," Ceramics International, Vol. 28, No. 4, 2002, pp. 363-367. doi:10.1016/S0272-8842(01)00103-1

[12] Z. Zhong, Q. Li, Y. L. Zhang, H. S. Zhong, M. Cheng and Y. Zhang, "Synthesis of Nanocrystalline Ni-Zn Ferrite Powders by Refluxing Method,” Powder Technology, Vol. 155, No. 3, 2005, pp. 193-195. doi:10.1016/j.powtec.2005.05.060

[13] A. Dias and R. L. Moreira, "Chemical, Mechanical and Dielectric Properties after Sintering of Hydrothermal Nickel-Zinc Ferrites,” Materials Letters, Vol. 39, No. 1, 1999, pp. 69-76. doi:10.1016/S0167-577X(98)00219-5

[14] S. E. Jacobo, S. Duhalde and H. R. Bertorello, "Rare Earth Influence on the Structural and Magnetic Properties of NiZn Ferrites," Journal of Magnetism and Magnetic Materials, Vol. 272-276, No. 3, 2004, pp. 2253-2254.

[15] S. D. Shenoy, P. A. Joy and M. R. Anantharaman, "Effect of Mechanical Milling on the Structural, Magnetic and Dielectric Properties of Coprecipitated Ultrafine Zinc Ferrite," Journal of Magnetism and Magnetic Materials, Vol. 269, No. 2, 2004, pp. 217-226. doi:10.1016/S0304-8853(03)00596-1

[16] S. A. Morrison, C. L. Cahill, E. E. Carpenter, S. Calvin, R. Swaminathan, M. E. McHenry and V. G. Harris, "Magnetic and Structural Properties of Nickel Zinc Ferrite Nanoparticles Synthesized at Room Temperature,” Journal of Applied Physics, Vol. 95, 2004, pp. 6392-6395. doi:10.1063/1.1715132 
[17] J. J. Sun, J. B. Li, G. L. Sun and W. G. Qu, "Synthesis of Dense NiZn Ferrites by Spark Plasma sintering,” Ceramics International, Vol. 28, No. 8, 2002, pp. 855-858. doi:10.1016/S0272-8842(02)00064-0

[18] A. Verma, T. C. Goel, R. G. Mendiratta and M. I. Alam, "Dielectric Properties of NiZn Ferrites Prepared by the Citrate Precursor Method,” Materials Science and Engineering: $B$, Vol. 60, No. 2, 1999, pp. 156-162. doi:10.1016/S0921-5107(99)00019-7

[19] G. P. Lópeza, S. P. Silvetti, S. E. Urreta and E. D. Cabanillas, "Magnetic Interactions in High-Energy Ball-Milled $\mathrm{NiZnFe}_{2} \mathrm{O}_{4} / \mathrm{SiO}_{2}$ Composites," Physica B: Condensed Matter, Vol. 398, No. 2, 2007, pp. 241-244. doi:10.1016/j.physb.2007.04.024

[20] C. Upadhyay, D. Mishra, H. C. Verma, S. Anand and R. P. Das, "Effect of Preparation Conditions on Formation of Nanophase Ni-Zn Ferrites through Hydrothermal Technique," Journal of Magnetism and Magnetic Materials, Vol. 260, No. 1-2, 2003, pp. 188-194. doi:10.1016/S0304-8853(02)01320-3

[21] M. J. Iqbal, M. N. Ashiq, P. Hernandez-Gomezb and J. M. Munoz, "Synthesis, Physical, Magnetic and Electrical Properties of Al-Ga Substituted Co-precipitated Nanocrystalline Strontium Hexaferrite,” Journal of Magnetism and Magnetic Materials, Vol. 320, No. 6, pp. 881-886. doi:10.1016/j.jmmm.2007.09.005

[22] L. Vegard, "Die Konstitution der Mischkristalle und die Raumfüllung der Atome," Zeitschrift für Physik a Hadrons and Nuclei, Vol. 5, 1921, pp. 17-26.

[23] Y.-P. Fu and S.-H. Wu, "Electrical and Magnetic Properties of Magnesium-Substituted," Ceramics International, Vol. 36, 2010, pp. 1311-1317.
[24] R. G. Kharake, R. S. Devan and B. K. Chougalu, "Structural And Electrical Properties Of Cd-Sub-stituted Li-Ni Ferrites," Journal of Alloys Compounds, Vol. 463, No. 1-2, 2008, pp. 67-72.

[25] B. R. Karache, B. V. Khasbardar and A. S. Vanigam, "X-Ray, SEM and Magnetic Properties of Mg-Cd Ferrites,” Journal of Magnetism and Magnetic Materials, Vol. 168, No. 3, 1997, pp. 292-298. doi:10.1016/S0304-8853(96)00705-6

[26] R. D Shannon and C. T. Prewitt, "Revised Values of Effective Ionic Radii,” Acta Crystallographica Section B, Vol. 26, Part 7, 1970, pp. 1046-1048.

[27] P. Kishan, D. R. Sagar and P. Swar, "Electrical Conduction and Dielectric Behaviour in Zinc-Substituted Lithium Ferrites,” Journal of Less Common Metals, Vol. 108, No. 2, 1985, pp. 345-351.

[28] Z. H. Zoha, “Ferrites, Magnetic Materials,” Science Publishing House, Beijing, 1978.

[29] A. A. Sattar, A. H. Wafik, K. M. El-Shokrofy and M. M. El-Tabby, "Magnetic Properties of Cu-Zn Ferrites Doped with Rare Earth Oxides,” Physica Status Solidi (a), Vol. 171, No. 2, 1999, pp. 563-569.

[30] S. Singhal and K. Chandra, "Cation Distribution and Magnetic Properties in Chromium-Substituted Nickel Ferrites Prepared Using Aerosol Route,” Journal of Solid State Chemistry, Vol. 180, No. 1, 2007, pp. 296-300.

[31] K. B Modi, H. H. Joshi and R. G. Kulkarni, "Magnetic Ordering in a Zn-Substituted Cu-Fe-Cr-O Ferrite System,” Indian Journal of Pure \& Applied Physics, Vol. 34, 1996, p. 93. 